\title{
Synthesis of nanocrystalline $\mathrm{TiB}_{2}$ powder from $\mathrm{TiO}_{2}, \mathrm{~B}_{2} \mathrm{O}_{3}$ and $\mathrm{Mg}$ reactants through microwave-assisted self-propagating high-temperature synthesis method
}

\author{
A GHANBARI ${ }^{1}$,M SAKAKI ${ }^{1, *}$, A FAEGHINIA ${ }^{2}$,M SH BAFGHI ${ }^{3,5}$ and K YANAGISAWA ${ }^{4}$ \\ ${ }^{1}$ Department of Materials Engineering, Faculty of Engineering, Malayer University, Malayer 65719-95863, Iran \\ ${ }^{2}$ Ceramic Division, Materials and Energy Research Center (MERC), Tehran 14155-4777, Iran \\ ${ }^{3}$ School of Metallurgy and Materials Engineering, Iran University of Science and Technology (IUST), Narmak, Tehran \\ 16846-13114, Iran \\ ${ }^{4}$ Research Laboratory of Hydrothermal Chemistry, Faculty of Science, Kochi University, Kochi 780-8520, Japan \\ ${ }^{5}$ Present address: Research Laboratory of Hydrothermal Chemistry, Faculty of Science, Kochi University, Kochi \\ 780-8520, Japan
}

MS received 13 December 2015; accepted 2 February 2016

\begin{abstract}
In this research work, microwave-assisted self-propagating high-temperature synthesis (SHS) process was employed for the fabrication of titanium diboride $\left(\mathrm{TiB}_{2}\right)$ compound from $\mathrm{TiO}_{2}-\mathrm{B}_{2} \mathrm{O}_{3}-\mathrm{Mg}$ mixtures. Thermodynamic evaluations of this system and its relevant subsystems revealed that $\mathrm{TiB}_{2}-\mathrm{MgO}$ composite powder can be easily produced by a SHS reaction. However, experimental results of a $\mathrm{TiO}_{2}: \mathrm{B}_{2} \mathrm{O}_{3}: 5 \mathrm{Mg}$ mixture heated in a domestic oven showed the formation of some intermediate compounds such as $\mathrm{Mg}_{3} \mathrm{~B}_{2} \mathrm{O}_{6}$, presumably due to some degree of $\mathrm{Mg}$ loss. The optimum amount of $\mathrm{Mg}$ in $\mathrm{TiO}_{2}: \mathrm{B}_{2} \mathrm{O}_{3}: x \mathrm{Mg}$ mixtures, yielding the highest amount of $\mathrm{TiB}_{2}$ phase, was found to be around $7 \mathrm{~mol}$, i.e., $40 \mathrm{~mol} \%$ more than the stoichiometric amount. Experimental results revealed that a pure $\mathrm{TiB}_{2}$ compound could be obtained by leaching the unwanted by-products in an $\mathrm{HCl}$ acid solution. Scanning electron microscopic observations and Scherrer calculations showed that the produced $\mathrm{TiB}_{2}$ contains sub-micron $(150-200 \mathrm{~nm})$ particles, where each particle consists of a number of nanosized (32 nm) crystallites.
\end{abstract}

Keywords. Titanium diboride; thermodynamic calculations; microwave processing; combustion synthesis.

\section{Introduction}

Titanium diboride $\left(\mathrm{TiB}_{2}\right)$, the most stable intermetallic compound of titanium and boron, has excellent properties such as high melting point and hardness, good thermal conductivity and stability together with high chemical and abrasive resistance. It can be used as cutting tools, abrasives, turbine blades as well as a cathode in aluminium smelting. As a reinforcement agent, $\mathrm{TiB}_{2}$ improves the mechanical properties of sintered bodies [1-4].

$\mathrm{TiB}_{2}$ can be commercially synthesized by carbothermic reduction of a $\mathrm{TiO}_{2}-\mathrm{B}_{2} \mathrm{O}_{3}$ mixture (equation (1)). This method requires a long time heating at high temperatures which makes the process very costly, therefore $[5,6]$

$$
\mathrm{TiO}_{2}+\mathrm{B}_{2} \mathrm{O}_{3}+5 \mathrm{C}=\mathrm{TiB}_{2}+5 \mathrm{CO}(\mathrm{g}) \text {. }
$$

In recent times, some inexpensive methods/reagents have been proposed for the synthesis of $\mathrm{TiB}_{2}$ compound, including chemical vapour deposition [7], sol-gel processing [8], solvothermal synthesis [9], mechanical alloying [10], thermal plasma process [11] and self-propagating high-temperature synthesis (SHS) method.

\footnotetext{
*Author for correspondence (masoudsakaki79@gmail.com, masoud_sakaki@iust.ac.ir)
}

The last method (SHS) named also as combustion synthesis (CS), utilizes the exothermicity of chemical reactions to promote the synthesis process [12-15]. To predict the possibility of use of SHS technique for the synthesis of a compound, thermodynamic calculations are of a noticeable help $[16,17]$. According to Merzhanov's criterion, the type of reaction is SHS, if its adiabatic temperature $\left(T_{\mathrm{ad}}\right.$ : highest temperature of the system under adiabatic condition) is higher than $1800 \mathrm{~K}$ [16]. In general, SHS reactions are triggered by using: (i) a furnace or (ii) an electrical element touching the surface of a green sample. Some advantages of SHS route can be summarized as: high production rate, simplicity, low energy consumption and good purity of the products $[12,13]$. SHS method has been recognized as a promising synthesis method for the fabrication of various advanced ceramics, e.g., carbides, nitrides and borides.

SHS synthesis of $\mathrm{TiB}_{2}$ composite materials containing either $\mathrm{MgO}$ or $\mathrm{Al}_{2} \mathrm{O}_{3}$ from $\mathrm{TiO}_{2}-\left(\mathrm{B}_{2} \mathrm{O}_{3} / \mathrm{H}_{3} \mathrm{BO}_{3}\right)-(\mathrm{Mg} / \mathrm{Al})$ reagents has been studied by various research groups [1829]. It has been found that a SHS reaction gets promoted if $\mathrm{Mg}$ is used as the reducing agent [23]; while in the case of $\mathrm{Al}$, addition of a mechanical activation step is necessary for the successful reaction ignition [30]. Moreover, it has been shown that some by-product phases, such as $\mathrm{Mg}_{3} \mathrm{~B}_{2} \mathrm{O}_{6}$, $\mathrm{Mg}_{2} \mathrm{TiO}_{4}, \mathrm{AlB}_{2}$ and $\mathrm{TiAl}_{3}$ could be formed [23,25,26]. These 
unwanted phases can be reduced or eliminated by precise control of the initial composition of reactants mixture as well as proper adjustment of synthesis conditions [23,25]. Moreover, addition of diluents such as $\mathrm{NaCl}$ results in a lower adiabatic temperature with the consequence of grain refinement of the final product [27]. It has been reported that use of $\mathrm{Mg}$ as the reducing agent is preferred for the fabrication of pure $\mathrm{TiB}_{2}$ phase due to the ease of elimination of $\mathrm{MgO}$ through acid leaching of $\mathrm{TiB}_{2}-\mathrm{MgO}$ powder [29].

In recent times, microwave energy has been used for triggering the SHS systems [31-34]. Since in microwave heating, heat is generated within the materials, it is totally different from the conventional heating methods. Internal heat generation during microwave heating brings about a uniform heat distribution in the samples, resulting in a more homogeneous product. Other advantages of microwave energy as the heating source are ability of selective heating, shortening the time/cost of the process together with less environmental pollution [35-37]. The efficiency of microwave heating is controlled by heat conductivity and dielectric properties of the target, microwave frequency and power, as well as operating temperature $[38,39]$.

Microwave-assisted SHS synthesis of $\mathrm{TiB}_{2}-\mathrm{Al}_{2} \mathrm{O}_{3}$ composite powder has been reported by Farhadinia [40] and Mousavian [41]. They have shown that for a successful synthesis, mechanical activation of reagents is required. Since leaching of $\mathrm{Al}_{2} \mathrm{O}_{3}$ phase from the fabricated $\mathrm{TiB}_{2}-\mathrm{Al}_{2} \mathrm{O}_{3}$ composite is not a simple process, production of a pure $\mathrm{TiB}_{2}$ phase cannot be easily achieved. It would be reasonable therefore, to search for other convenient reducing agents.

In this research work, production of nanocrystalline $\mathrm{TiB}_{2}$ phase from $\mathrm{TiO}_{2}-\mathrm{B}_{2} \mathrm{O}_{3}-\mathrm{Mg}$ reagents through microwave-assisted SHS synthesis route has been studied. Thermodynamic calculations were used for the prediction of the behaviour of possible reactions. Several synthesis experiments were performed in a domestic microwave oven to find out the optimum initial composition. In addition, to produce a pure $\mathrm{TiB}_{2}$ phase, by-product compounds were leached away by using a dilute $\mathrm{HCl}$ solution. Microstructure of the optimum product was examined by a scanning electron microscope (SEM) and its crystallite size was evaluated by applying the Scherrer equation [42].

\section{Experimental}

The aim of this study is the production of pure $\mathrm{TiB}_{2}$ phase through microwave-assisted SHS reaction. Thermodynamic calculations were performed to predict the possibility as well as the mode of probable reactions. For this purpose, $\Delta G^{0}$, $\Delta H^{0}$ and $T_{\text {ad }}$ values have been computed by the use of available thermodynamic data [43].

Experimental investigations were performed using analytical grade $\mathrm{TiO}_{2}, \mathrm{~B}_{2} \mathrm{O}_{3}$ and $\mathrm{Mg}$ powders. Reagents were mixed by hand and pressed into green cylindrical samples $(10 \mathrm{~mm}$ diameter and $4 \mathrm{~mm}$ height) by an axial hydraulic pressing device.

Microwave heating was performed by use of a domestic microwave oven (Samsung: GE2370G, 850 W output power). Since the capability of the green samples for absorption of microwave energy was unacceptably low, a block of microwave energy absorbing silicon carbide $(\mathrm{SiC})$ was located under the samples to promote the synthesis process. Figure 1 represents the schematic illustration of the experimental set-up. Our investigations and experiences showed that $\mathrm{Al}_{2} \mathrm{O}_{3}$ and $\mathrm{SiO}_{2}$ are transparent to microwave radiation and therefore, would not affect the heating efficiency. They were merely used to prevent air infiltration to the reaction vicinity.

Samples were heated-up to initiate SHS reaction. Observation of specific physical phenomena (e.g., flaming and flushing of samples) were the signs of reaction occurrence and progress. After SHS reaction, microwave device was turned off and the set-up was left to be cooled down slowly. Produced powder was grounded in an alumina mortar and its composition was identified by an X-ray diffraction instrument (XRD: Unisantis-XMD 300, CuK $\alpha$ radiation). Acid leaching step was done by a dilute $\mathrm{HCl}$ solution under a moderate stirring condition. The temperature and stirring time were fixed at $50^{\circ} \mathrm{C}$ and $2 \mathrm{~h}$, respectively.

Microstructure and chemical composition of the product were evaluated by a SEM machine (TESCAN-VEGA II) equipped with an energy-dispersive X-ray spectrometer (EDX). For this purpose, the powder was dispersed in ethanol by ultrasonic vibration. Then, one droplet of the suspension was placed on a piece of glass, which will be coated with $\mathrm{Au}$ after the ethanol evaporation.

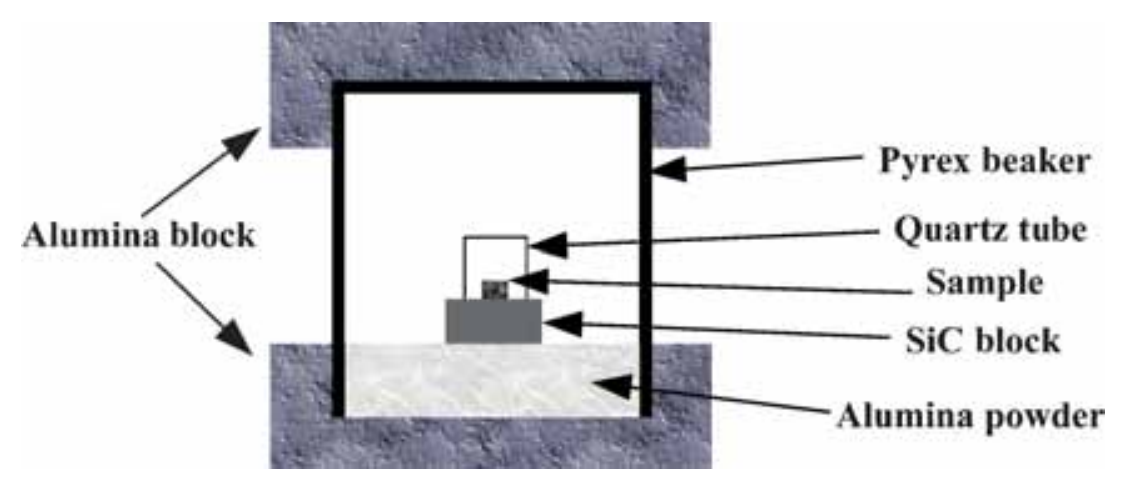

Figure 1. Schematic of the experimental set-up. 
Crystallite size of the product was calculated by use of the Scherrer equation

$$
d=0.9 \lambda /[(\beta \cdot \cos (\theta)],
$$

where $d$ is the crystallite size, $\lambda$ the wavelength of X-ray radiation, $\beta$ the peak width at half-maximum height and $\theta$ the diffraction angle.

\section{Results and discussion}

\subsection{Thermodynamic calculations}

The overall reaction in $\mathrm{TiO}_{2}-\mathrm{B}_{2} \mathrm{O}_{3}-\mathrm{Mg}$ system could be written as follows:

$$
\mathrm{TiO}_{2}+\mathrm{B}_{2} \mathrm{O}_{3}+5 \mathrm{Mg}=\mathrm{TiB}_{2}+5 \mathrm{MgO} .
$$

In fact, equation (3) is the sum of magnesiothermic reduction reactions of $\mathrm{TiO}_{2}$ and $\mathrm{B}_{2} \mathrm{O}_{3}$ (equations (4) and (5)) together with the reaction between reduced $\mathrm{Ti}$ and $\mathrm{B}$ (equation (6)).

$$
\begin{aligned}
& \mathrm{TiO}_{2}+2 \mathrm{Mg}=\mathrm{Ti}+2 \mathrm{MgO}, \\
& \mathrm{B}_{2} \mathrm{O}_{3}+3 \mathrm{Mg}=2 \mathrm{~B}+3 \mathrm{MgO},
\end{aligned}
$$

$\mathrm{Ti}+2 \mathrm{~B}=\mathrm{TiB}_{2}$

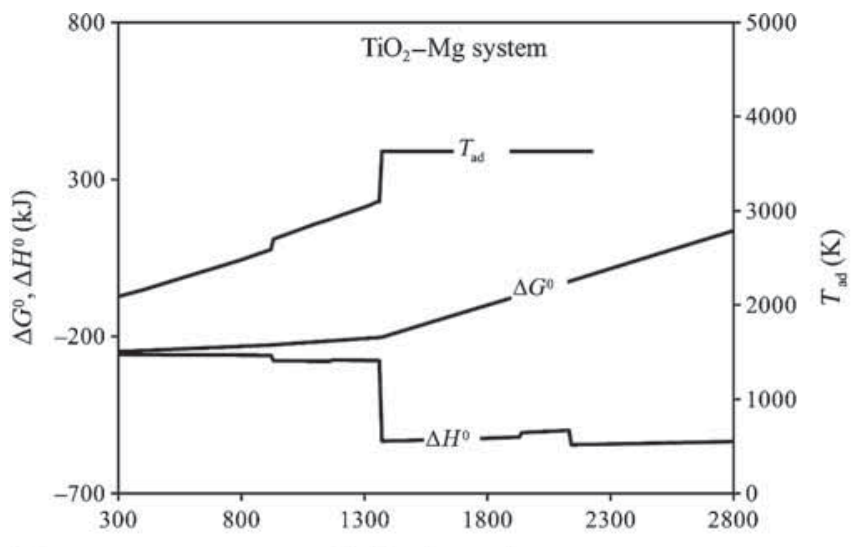

(a)

Starting temperature

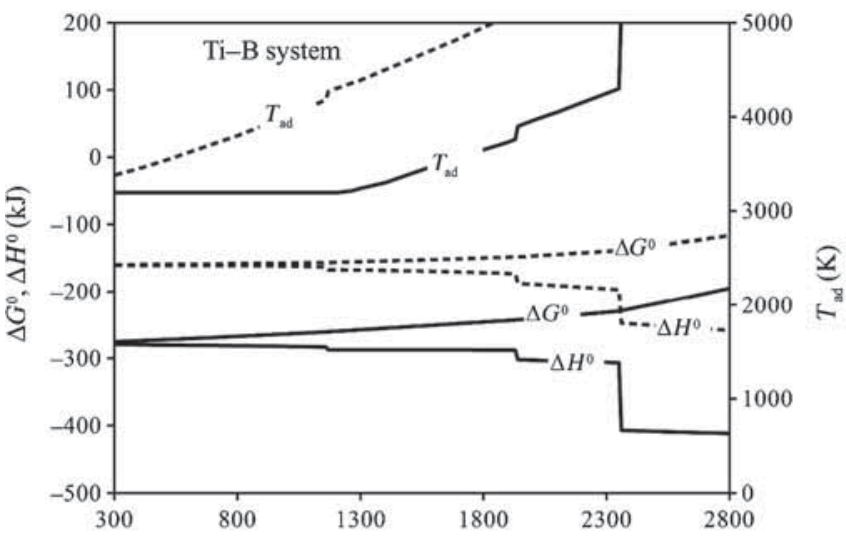

(c)

Starting temperature
To gain an insight into equation (3), values of $\Delta G^{0}, \Delta H^{0}$ and $T_{\text {ad }}$ of its sub-reactions (i.e., equations (4)-(6)) were calculated. The results are presented in the following sections.

3.1a $\mathrm{TiO}_{2}-\mathrm{Mg}$ system: Transformation temperature of starting materials and products of equations (4)-(6) should be taken into account during thermodynamic calculations. Table 1 shows these phase change temperatures. Figure $2 \mathrm{a}$

Table 1. Possible phase transformations of raw materials and products of equations (4)-(6).

Transformation Temperature (K)

$\mathrm{B}_{2} \mathrm{O}_{3}(\mathrm{~s}) \leftrightarrow \mathrm{B}_{2} \mathrm{O}_{3}$ (l)

$\mathrm{Mg}(\mathrm{s}) \leftrightarrow \mathrm{Mg}(\mathrm{l})$

923

$\mathrm{Ti}\left(\mathrm{s}_{1}\right) \leftrightarrow \mathrm{Ti}\left(\mathrm{s}_{2}\right)$

1166

$\operatorname{Mg}(1) \leftrightarrow \operatorname{Mg}(\mathrm{g})$

1367

$\operatorname{Ti}\left(\mathrm{s}_{2}\right) \leftrightarrow \mathrm{Ti}(\mathrm{l})$

1939

$\mathrm{TiO}_{2}(\mathrm{~s}) \leftrightarrow \mathrm{TiO}_{2}(\mathrm{l})$

2130

$\mathrm{B}_{2} \mathrm{O}_{3}(\mathrm{l}) \leftrightarrow \mathrm{B}_{2} \mathrm{O}_{3}(\mathrm{~g})$

2330

$\mathrm{B}(\mathrm{s}) \leftrightarrow \mathrm{B}(\mathrm{l})$

2350

3098

MgO (1)

3193

3634

$\mathrm{Ti}(\mathrm{l}) \leftrightarrow \mathrm{Ti}(\mathrm{g})$

3771

$\mathrm{TiO}_{2}(\mathrm{l}) \leftrightarrow \mathrm{TiO}_{2}(\mathrm{~g})$

B (l) $\leftrightarrow$ B (g)

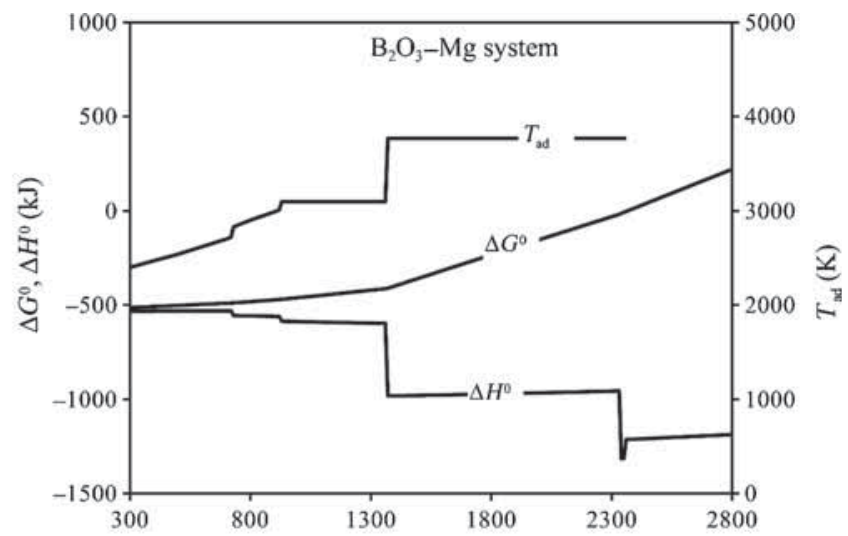

(b)

Starting temperature

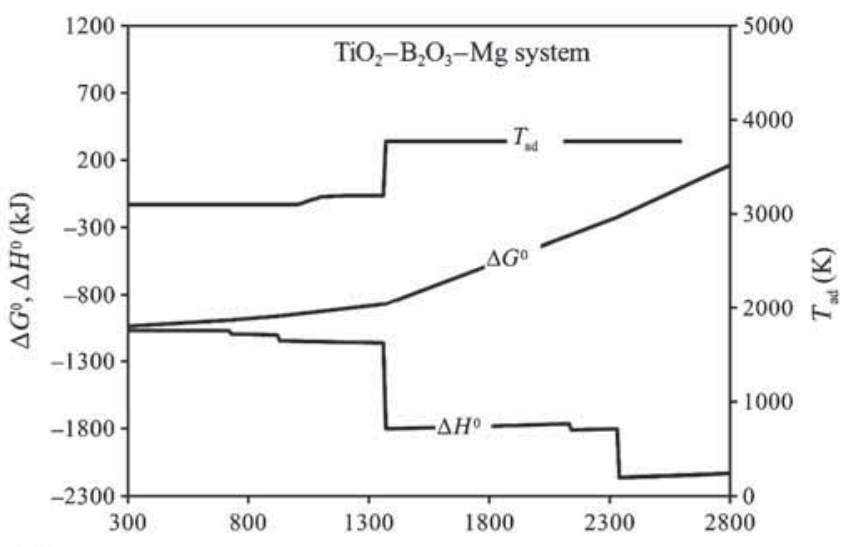

(d)

Starting temperature

Figure 2. $\Delta G^{0}, \Delta H^{0}$ and $T_{\mathrm{ad}}$ values of equations (3)-(7) vs. the starting temperature. 
represents the values of $\Delta G^{0}, \Delta H^{0}$ and $T_{\text {ad }}$ of equation (4) as a function of the starting temperature. Observed breaks at $923,1166,1367,1939,2130,3098$ and $3634 \mathrm{~K}$ are related to the phase transitions of $\mathrm{Mg}, \mathrm{Ti}, \mathrm{TiO}_{2}$ and $\mathrm{MgO}$, according to table 1. $\Delta G^{0}$ of equation (4) at $300 \mathrm{~K}$ is $-248.9 \mathrm{~kJ} \mathrm{~mol}^{-1}$, which is an indication of its high tendency for propagation. Although, the increase of $\Delta G^{0}$ by increasing the starting temperature indicates the reverse effect of temperature, negative values of $\Delta G^{0}$ in $300-2230 \mathrm{~K}$ range show that the reduction of $\mathrm{TiO}_{2}$ by $\mathrm{Mg}$ is still possible in this range. According to figure $2 \mathrm{a}$, equation (4) becomes thermodynamically impossible above $2230 \mathrm{~K}$. As figure 2a shows, equation (4) is very exothermic $\left(\Delta H^{0}=-258.2 \mathrm{~kJ} \mathrm{~mol}^{-1}\right)$ at $300 \mathrm{~K}$. Hence, it is expected that the temperature of whole mixture would be increased as a consequence of reaction propagation. Calculated results (figure 2a) confirm this expectation showing that $T_{\mathrm{ad}}$ of equation (4) starting from $300 \mathrm{~K}$, is as high as 2090 $\mathrm{K}$. Therefore, the type of equation (4) is SHS, according to Merzhanov's criterion [16]. Figure 2a also shows that the exothermicity of equation (4) goes higher by increasing the starting temperature. This in turn brings about a higher adiabatic temperature in the system. According to figure $2 \mathrm{a}$, when the starting temperature of the system is higher than $1370 \mathrm{~K}$, $T_{\text {ad }}$ reaches to $3634 \mathrm{~K}$ and then remains constant, expectedly as the consequence of liquid to gas phase transformation of reduced titanium (see table 1). $T_{\text {ad }}$ has not been calculated for starting temperatures beyond $2230 \mathrm{~K}$, because equation (4) becomes thermodynamically impossible, thereafter.

3.1b $\quad B_{2} O_{3}-M g$ system: Curves of $\Delta G^{0}, \Delta H^{0}$ and $T_{\mathrm{ad}}$ of equation (5) $v s$. starting temperature are shown in figure $2 \mathrm{~b}$. Again, breaks in figure $2 \mathrm{~b}$ are related to the relevant phase transformations shown in table $1 . \Delta G^{0}$ value at $300 \mathrm{~K}$ is $-514.7 \mathrm{~kJ}$ indicating the inherent tendency of the reaction to go forward. By increasing the initial temperature, $\Delta G^{0}$ value increases which is unfavourable for the reaction progress. $\Delta G^{0}$ value becomes positive at temperatures higher than $2360 \mathrm{~K}$ indicating that the reaction is impossible at such high temperature as per the thermodynamic viewpoint.

On the other hand, figure $2 \mathrm{~b}$ reveals that at $300 \mathrm{~K}$, equation (5) is very exothermic $\left(\Delta H^{0}=-532.6 \mathrm{~kJ}\right)$ and its adiabatic temperature is around $2400 \mathrm{~K}$. Hence, according to Merzhanov's criterion, the reaction would be of a SHS type. Similar to the $\mathrm{TiO}_{2}-\mathrm{Mg}$ system, by increasing the initial temperature, the exothermicity degree and adiabatic temperature of equation (5) were increased. Figure $2 \mathrm{~b}$ shows that the adiabatic temperature reaches to $3771 \mathrm{~K}$, when the initial temperature was $1370 \mathrm{~K}$.

3.1c Ti-B system: Regarding the above thermodynamic calculations, $\mathrm{TiO}_{2}$ and $\mathrm{B}_{2} \mathrm{O}_{3}$ are expected to be easily reduced by $\mathrm{Mg}$ during microwave heating of $\mathrm{TiO}_{2}-\mathrm{B}_{2} \mathrm{O}_{3}-$ $\mathrm{Mg}$ mixture. The reaction between reduced $\mathrm{Ti}$ and $\mathrm{B}$ (i.e., equations (6) and (7)) is examined, hereinafter

$$
\mathrm{Ti}+\mathrm{B}=\mathrm{TiB} .
$$

Figure 2c shows the calculated values of $\Delta G^{0}, \Delta H^{0}$ and $T_{\text {ad }}$ of equations (6) and (7) as a function of starting temperature. In this figure, continuous and dashed lines represent data belonging to equations (6) and (7), respectively. Considering this figure in conjunction with previous explanations, both reactions are thermodynamically possible and are exothermic. Values of $T_{\text {ad }}$ of equations (6) and (7) are higher than $1800 \mathrm{~K}$; therefore, both reactions are expected to proceed with a combustion mode. It is notable that for the whole range of starting temperature, $\Delta G^{0}$ value of equation (6) is lower than that of equation (7). Moreover, equation (6) is more exothermic. Hence, it can be concluded that the production of $\mathrm{TiB}_{2}$ (through equation (6)) is thermodynamically preferred.

Conclusion of thermodynamic evaluations: A comparison of figure $2 \mathrm{a}$ and $\mathrm{b}$ reveals that in $\mathrm{TiO}_{2}-\mathrm{B}_{2} \mathrm{O}_{3}-\mathrm{Mg}$ mixture, the chemical reaction is expected to be initiated by equation (5), which has a more negative $\Delta G^{0}$ value compared to equation (4). Afterwards, released heat of equation (5) will activate equations (4) and (6). In other words, $\mathrm{TiB}_{2}-\mathrm{MgO}$ composite will be formed through equation (3). The $\Delta G^{0}$, $\Delta H^{0}$ and $T_{\text {ad }}$ values of equation (3) are plotted in figure $2 \mathrm{~d}$, as a function of starting temperature. With regard to $\Delta G^{0}$ curve, the occurrence possibility of equation (3) in $\mathrm{TiO}_{2}-$ $\mathrm{B}_{2} \mathrm{O}_{3}-\mathrm{Mg}$ mixture is very high. Equation (3) is extremely exothermic, so that its type is SHS, according to Merzhanov's criterion. Hence, it could be concluded that from the thermodynamic standpoint, $\mathrm{TiB}_{2}-\mathrm{MgO}$ composite can be easily produced through the microwave-assisted SHS method.

\subsection{Experimental findings}

A summary of mixture compositions, heating times and experimental observations of all investigated samples is presented in table 2. Figure 3 shows an example of the shape of a typical sample, before and after the SHS reaction. The figure shows that after the combustion reaction, the volume of the initial compact has considerably increased and the product has gained a layered structure. These phenomena that have been observed in other SHS reaction studies, are supposed to be a physical consequence of the evolution of gaseous products from the compact at high system temperatures [44].

Figure 4a exhibits the XRD pattern of a sample obtained by heating $\mathrm{TiO}_{2}: \mathrm{B}_{2} \mathrm{O}_{3}: 5 \mathrm{Mg}$ mixture. No evidence of the starting materials is visible in this figure and the main detectable phases are $\mathrm{MgO}$ and $\mathrm{TiB}_{2}$. The existence of $\mathrm{MgO}$

Table 2. Composition, ignition time $\left(t_{\text {ig }}\right)$ and mode of reaction for various investigated $\mathrm{TiO}_{2}-\mathrm{B}_{2} \mathrm{O}_{3}-\mathrm{Mg}$ systems.

\begin{tabular}{lccc}
\hline $\begin{array}{l}\text { Sample } \\
\text { code }\end{array}$ & Composition & $t_{\text {ig }}(\mathrm{s})$ & $\begin{array}{c}\text { Reaction } \\
\text { type }\end{array}$ \\
\hline $\mathrm{A}$ & $\mathrm{TiO}_{2}: \mathrm{B}_{2} \mathrm{O}_{3}: 5 \mathrm{Mg}$ & 38 & SHS \\
$\mathrm{B}$ & $\mathrm{TiO}_{2}: \mathrm{B}_{2} \mathrm{O}_{3}: 6 \mathrm{Mg}$ & 57 & SHS \\
$\mathrm{C}$ & $\mathrm{TiO}_{2}: \mathrm{B}_{2} \mathrm{O}_{3}: 7 \mathrm{Mg}$ & 92 & SHS \\
$\mathrm{D}$ & $\mathrm{TiO}_{2}: \mathrm{B}_{2} \mathrm{O}_{3}: 8 \mathrm{Mg}$ & 97 & SHS \\
\hline
\end{tabular}




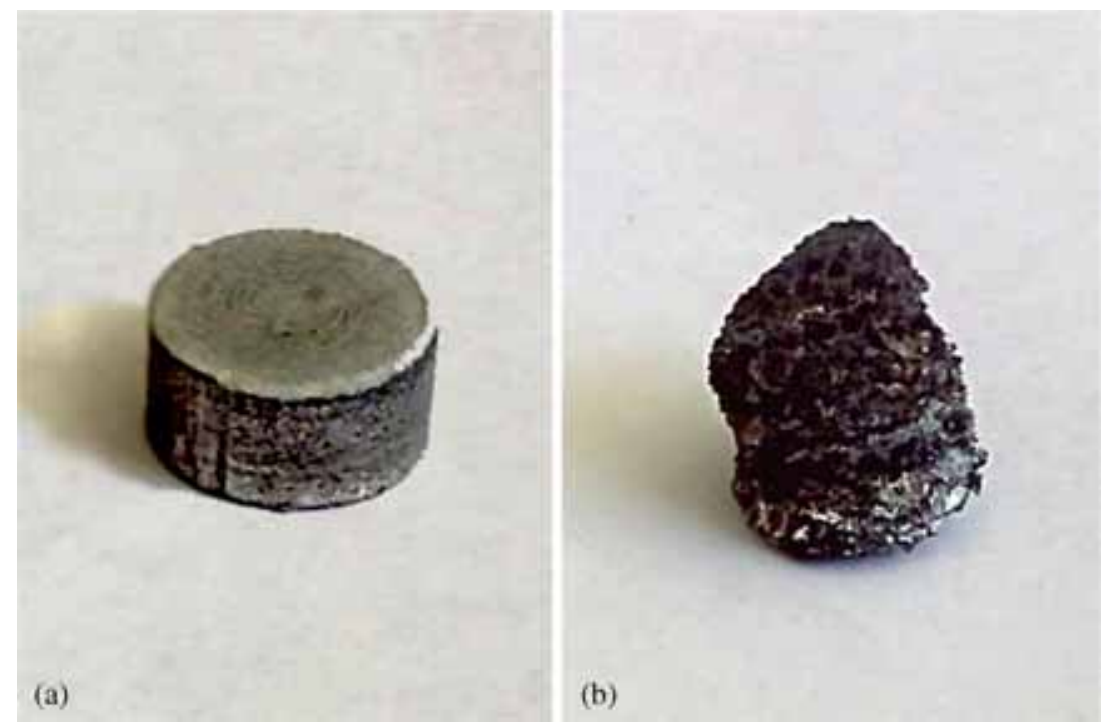

Figure 3. Shape of a typical sample (a) before and (b) after the SHS reaction.

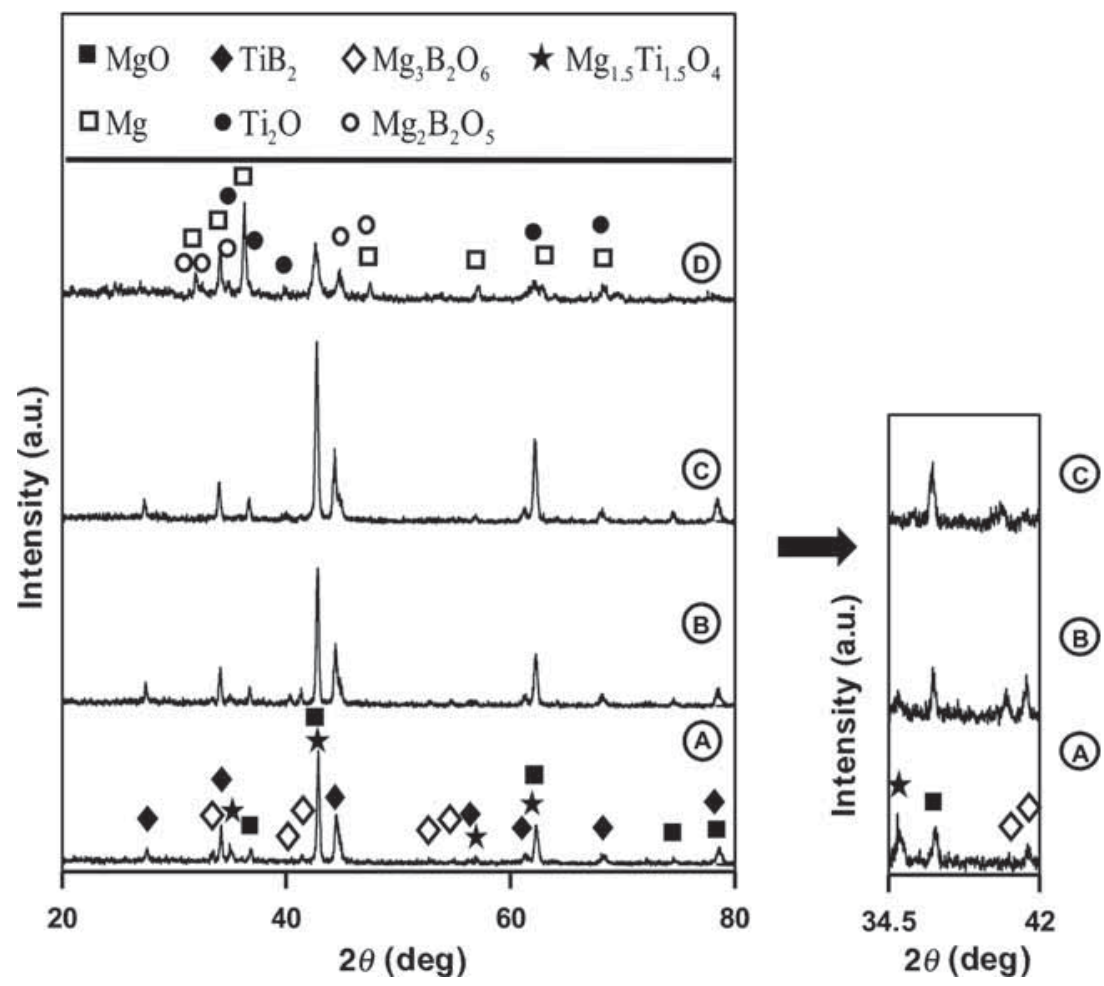

Figure 4. XRD patterns of heated $\mathrm{TiO}_{2}: \mathrm{B}_{2} \mathrm{O}_{3}: x \mathrm{Mg}$ mixtures. $\mathrm{A}: x=5, \mathrm{~B}: x=6$, $\mathrm{C}: x=7$ and D: $x=8$. The $34.5-42$ degree portion of the patterns A-C are separately shown with a higher magnification. The employed JCPDF cards for phase identification are: $\mathrm{MgO}: 00-004-0829, \mathrm{TiB}_{2}$ : 00-008-0121, $\mathrm{Mg}_{3} \mathrm{~B}_{2} \mathrm{O}_{6}$ : 00-038-1475, $\mathrm{Mg}_{1.5} \mathrm{Ti}_{1.5} \mathrm{O}_{4}$ : 00-044-0086, Mg: 00-035-0821, $\mathrm{Ti}_{2} \mathrm{O}$ : 00-011-0218 and $\mathrm{Mg}_{2} \mathrm{~B}_{2} \mathrm{O}_{5}$ : 00-016-0168.

phase confirms the occurrence of magnesiothermic reduction reactions (equations (4) and (5)). Reaction type in this system has been SHS (see table 2), which is in agreement with the thermodynamic predictions. According to equation (3), it is expected that heating of $\mathrm{TiO}_{2}: \mathrm{B}_{2} \mathrm{O}_{3}: 5 \mathrm{Mg}$ mixture will yield a $\mathrm{TiB}_{2}-\mathrm{MgO}$ composite powder. However, other by-products (such as $\mathrm{Mg}_{3} \mathrm{~B}_{2} \mathrm{O}_{6}$ ) are visible in figure 4a, whose existence could be attributed to $\mathrm{Mg}$ deficiency in the system due to the following phenomena:

(i) Partial oxidation of $\mathrm{Mg}$ as a result of some oxygen leakage into the reaction chamber. 
(ii) Partial escape of vapourized magnesium (boiling point $=1367 \mathrm{~K})$ at high system temperatures.

$\mathrm{Mg}$ deficiency causes incomplete reduction of initial oxide phases. Hence, some $\mathrm{TiO}_{2}$ and $\mathrm{B}_{2} \mathrm{O}_{3}$ reagents remain in the system. By-products observable in figure 4a, are supposed to be formed as a result of the reaction of $\mathrm{MgO}$ (produced in reduction reactions) with the remained $\mathrm{TiO}_{2}$ and $\mathrm{B}_{2} \mathrm{O}_{3}$ oxides

$$
\begin{aligned}
& 3 \mathrm{TiO}_{2}+\mathrm{Mg}=\mathrm{Ti}_{3} \mathrm{O}_{5}+\mathrm{MgO}, \\
& \mathrm{Ti}_{3} \mathrm{O}_{5}+3 \mathrm{MgO}=2 \mathrm{Mg}_{1.5} \mathrm{Ti}_{1.5} \mathrm{O}_{4}, \\
& 3 \mathrm{MgO}+\mathrm{B}_{2} \mathrm{O}_{3}=\mathrm{Mg}_{3} \mathrm{~B}_{2} \mathrm{O}_{6} .
\end{aligned}
$$

According to the above justification, $\mathrm{Mg}_{3} \mathrm{~B}_{2} \mathrm{O}_{6}$ and $\mathrm{Mg}_{1.5} \mathrm{Ti}_{1.5} \mathrm{O}_{4}$ formations could be prevented by use of higher $\mathrm{Mg}$ amounts in the $\mathrm{TiO}_{2}-\mathrm{B}_{2} \mathrm{O}_{3}-\mathrm{Mg}$ mixture.

Table 2 shows that the reactions type has not been affected by the amounts of $\mathrm{Mg}$ in $\mathrm{TiO}_{2}: \mathrm{B}_{2} \mathrm{O}_{3}: x \mathrm{Mg}$ mixtures, so that all reactions have SHS behaviour. Nevertheless, due to the microwave radiation reflection by metals [37], it is expected that by increasing the metal content in the mixture, the energy absorption efficiency and consequently the system temperature will be decreased; causing a delay in SHS reaction initiation. Confirmation proof of this postulation is seen in table 2 .

Figure 4b-d shows the XRD patterns of samples, synthesized by various amounts of $\mathrm{Mg}$ in $\mathrm{TiO}_{2}: \mathrm{B}_{2} \mathrm{O}_{3}: x \mathrm{Mg}$ mixtures. By increasing the initial $\mathrm{Mg}$ content from 1 to 1.4 times of its stoichiometric amount (i.e., from 5 to 7 moles) the peak heights (intensities) of by-products have decreased (compare patterns A, B and C). Considering the proposed reaction mechanism, this phenomenon is probably due to further reduction of $\mathrm{B}_{2} \mathrm{O}_{3}$ and $\mathrm{TiO}_{2}$, which diminishes equations (8)-(10). The promising effect of increasing $\mathrm{Mg}$ contents of $\mathrm{TiO}_{2}: \mathrm{B}_{2} \mathrm{O}_{3}: x \mathrm{Mg}$ mixtures on the formation of $\mathrm{TiB}_{2}$ compound could also be seen in figure 5, where $I_{\text {preferred phase }} / I_{\text {unwanted phases }}$ has been used as a scale for the evaluation of overall reaction (equation (3)) completeness.

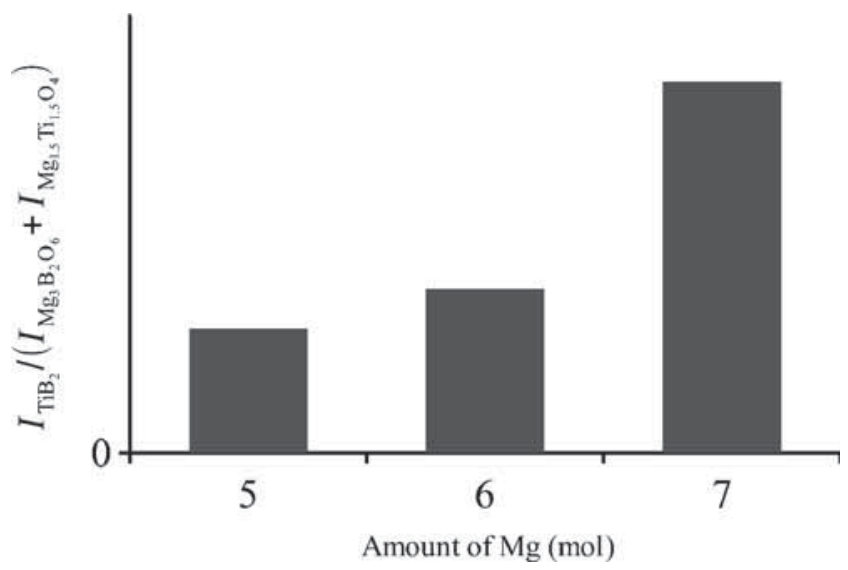

Figure 5. Effect of initial $\mathrm{Mg}$ amounts in $\mathrm{TiO}_{2}: \mathrm{B}_{2} \mathrm{O}_{3}: x \mathrm{Mg}$ mixtures on the $I_{\text {preferred phase }} / I_{\text {unwanted phase }}$ ratio.
The presence of unwanted by-products in the pattern 4$\mathrm{C}$ reveals that the use of higher $\mathrm{Mg}$ amounts is necessary. Nevertheless, by using 8 moles of magnesium (i.e., 1.6 times of the stoichiometric amount) peaks of by-products are still observable in the XRD pattern (figure 4d), together with peaks of unreacted magnesium. A possible reason may be the reflective characteristic of $\mathrm{Mg}$ towards microwave energy that prevents the whole system from effective energy absorption; so that the reaction cannot takes place completely and some $\mathrm{Mg}$ remains unreacted. Therefore, it may be concluded that the optimum amount of $\mathrm{Mg}$ in $\mathrm{TiO}_{2}: \mathrm{B}_{2} \mathrm{O}_{3}: x \mathrm{Mg}$ mixtures, which yields the highest amount of $\mathrm{TiB}_{2}$ and the lowest amounts of unwanted by-products, is around about 1.4 times of the stoichiometric amount.

To produce a pure $\mathrm{TiB}_{2}$ compound, the product obtained from the heating of $\mathrm{TiO}_{2}: \mathrm{B}_{2} \mathrm{O}_{3}: 7 \mathrm{Mg}$ mixture was leached

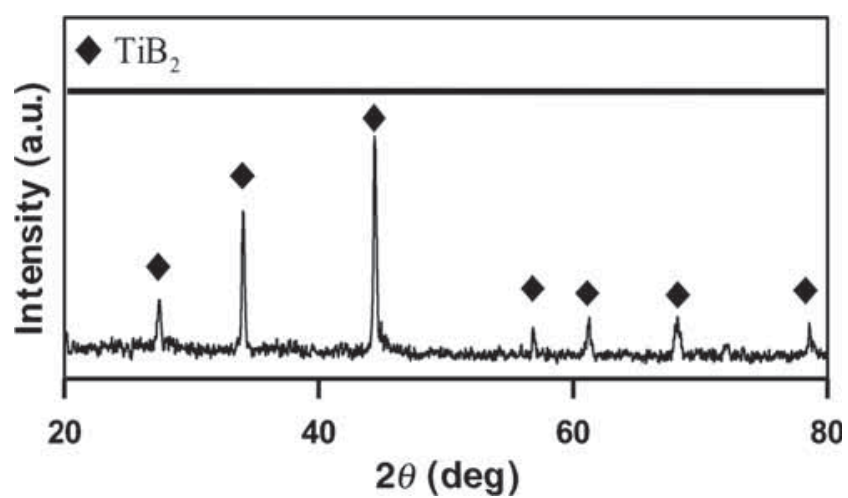

Figure 6. XRD pattern of pure $\mathrm{TiB}_{2}$ phase (JCPDF card: 00-008-0121) obtained by acid leaching of the $\mathrm{TiO}_{2}: \mathrm{B}_{2} \mathrm{O}_{3}$ : $7 \mathrm{Mg}$ system reaction product.

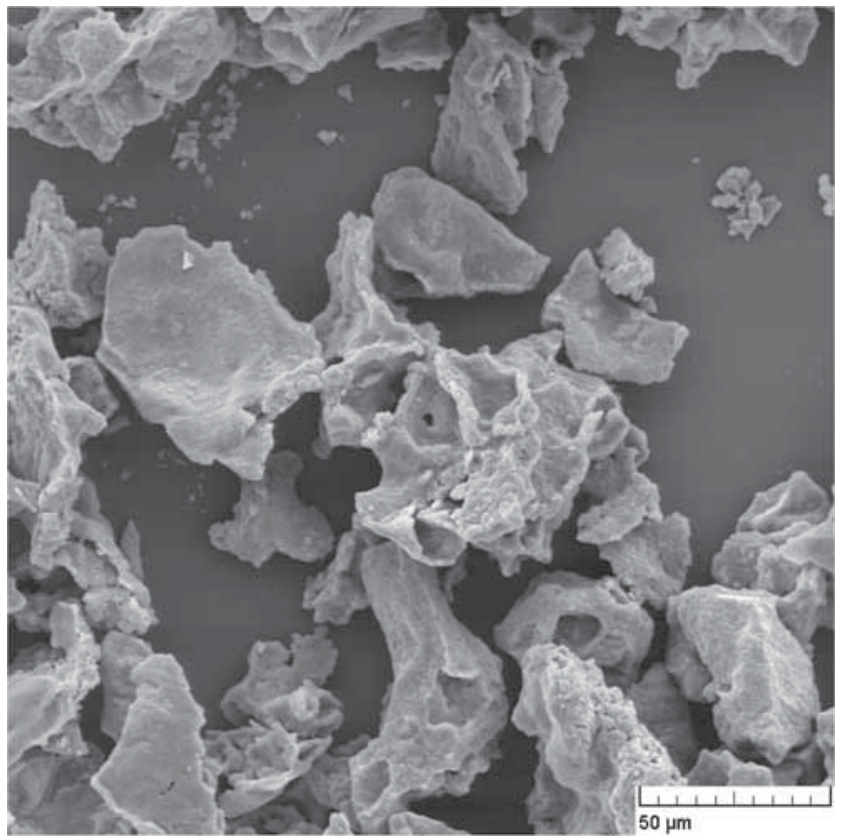

Figure 7. SEM image $(1000 \times)$ of $\mathrm{TiO}_{2}: \mathrm{B}_{2} \mathrm{O}_{3}: 7 \mathrm{Mg}$ system reaction product. 


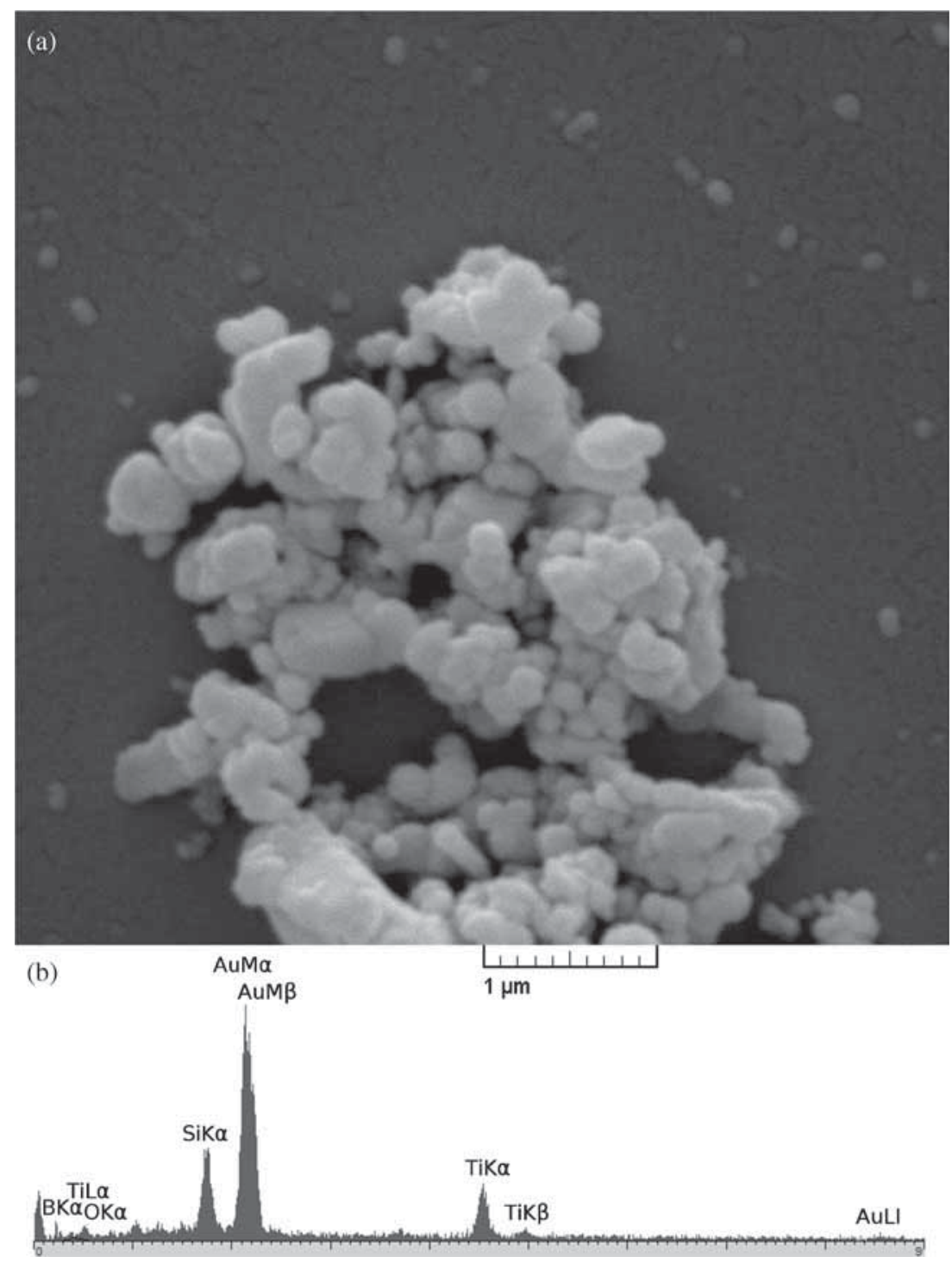

Figure 8. (a) SEM image $(40,000 \times)$ and (b) EDX data of the acid leached product of $\mathrm{TiO}_{2}: \mathrm{B}_{2} \mathrm{O}_{3}: 7 \mathrm{Mg}$ system.

in a dilute $\mathrm{HCl}$ solution. Figure 6 displays the XRD pattern of a heated $\mathrm{TiO}_{2}: \mathrm{B}_{2} \mathrm{O}_{3}: 7 \mathrm{Mg}$ sample after acid leaching. It could be seen that all by-product compounds have been successfully eliminated and the remaining powder is solely a $\mathrm{TiB}_{2}$ phase.

\subsection{Morphology and microstructure}

Figure 7 shows the SEM image of a $\mathrm{TiO}_{2}: \mathrm{B}_{2} \mathrm{O}_{3}: 7 \mathrm{Mg}$ mixture, after the SHS reaction. As can be seen, the product consists of large agglomerates. Probably, the high temperature of SHS reaction has caused some partial sintering and agglomeration [31].

The SEM image of heated and leached $\mathrm{TiO}_{2}: \mathrm{B}_{2} \mathrm{O}_{3}: 7 \mathrm{Mg}$ mixture is presented in figure $8 \mathrm{a}$, where the mean particle size is estimated as in the range of $150-200 \mathrm{~nm}$. Formation of these fine (sub-micron) particles from the very large initial agglomerates (figure 7) can be attributed to the
Table 3. Calculated crystallite size of produced $\mathrm{TiB}_{2}$ phase.

\begin{tabular}{lc}
\hline $2 \theta(\mathrm{deg})$ & Crystallite size $(\mathrm{nm})$ \\
\hline 27.47 & 30.1 \\
34.06 & 33.5 \\
44.38 & 30.3 \\
61.23 & 32.6 \\
\hline
\end{tabular}

Note: Mean crystallite size (nm): 31.6.

boundary breakage during the acid leaching process $[45,46]$. Figure $8 \mathrm{~b}$ shows the result of EDX analysis of the mentioned sample. $\mathrm{Si}, \mathrm{O}$ and Au peaks in EDX analysis data are originated from the base glass and Au coating used for sample preparation. The absence of $\mathrm{Mg}$ peak in the EDX result is in agreement with figure 6 , demonstrating the effectiveness of acid leaching practice for the complete elimination of unwanted phases from the product. 
Table 3 shows the diffraction angles and crystallites sizes of the produced $\mathrm{TiB}_{2}$ phase calculated by using four main peaks of figure 6 . The mean crystallite size of $\mathrm{TiB}_{2}$ phase is found to be around $32 \mathrm{~nm}$.

\section{Conclusion}

The aim of this research work has been the investigation of the possibility of fabrication of $\mathrm{TiB}_{2}$ compound from $\mathrm{TiO}_{2}-\mathrm{B}_{2} \mathrm{O}_{3}-\mathrm{Mg}$ mixture through microwave-assisted SHS in a low power (domestic) oven. Summary of thermodynamic evaluations and experimental findings are as follows:

(1) Over a wide range of starting temperature, magnesiothermic reduction of $\mathrm{TiO}_{2}$ and $\mathrm{B}_{2} \mathrm{O}_{3}$ via SHS reaction is thermodynamically possible. Titanium diboride is formed thereafter, through the reaction between the reduced $\mathrm{Ti}$ and $\mathrm{B}$.

(2) Experimental investigation of $\mathrm{TiO}_{2}: \mathrm{B}_{2} \mathrm{O}_{3}: 5 \mathrm{Mg}$ system showed that although $\mathrm{TiB}_{2}-\mathrm{MgO}$ composite is formed in this system, the product contains some amounts of unwanted intermediate phases such as $\mathrm{Mg}_{3} \mathrm{~B}_{2} \mathrm{O}_{6}$, whose formation presumably is originated from some degree of $\mathrm{Mg}$ deficiency in the system. It is believed that $\mathrm{Mg}$ deficiency is the result of magnesium loss due to either $\mathrm{Mg}$ vapourization at high system temperatures or its oxidation by infiltrated oxygen (air).

(3) Experimental investigations about $\mathrm{TiO}_{2}: \mathrm{B}_{2} \mathrm{O}_{3}: x \mathrm{Mg}$ mixtures showed that with the increase of initial $\mathrm{Mg}$ amounts up to $7 \mathrm{~mol}$ (40 mol\% excess), the amount of $\mathrm{TiB}_{2}$ phase in the product increases.

(4) Leaching in a dilute $\mathrm{HCl}$ acid solution was found effective for the purification of $\mathrm{TiO}_{2}: \mathrm{B}_{2} \mathrm{O}_{3}: 7 \mathrm{Mg}$ system product and obtaining a pure $\mathrm{TiB}_{2}$ phase.

(5) SEM observations showed that the products of SHS reactions are in the form of sintered, large and dense agglomerates, which consist of sub-micron $\mathrm{TiB}_{2}$ particles.

(6) Scherrer calculations showed that the mean crystallite size of the produced $\mathrm{TiB}_{2}$ is about $32 \mathrm{~nm}$.

(7) Good agreement was found between theoretical predictions and experimental findings.

\section{References}

[1] Wang H Y, Jiang Q C, Zhao Y Q, Zhao F, Ma B X and Wang Y 2004 Mater. Sci. Eng. A 372109

[2] Tang W M, Zheng Z X, Wu Y C, Wang J M, Lu J and Liu J W 2006 Trans. Nonferrous Met. Soc. China 16613

[3] Ziemnicka-Sylwester M 2013 Materials 61903

[4] Königshofer R, Fürnsinn S, Steinkellner P, Lengauer W, Haas R, Rabitsch K and Scheerer M 2005 Int. J. Refract. Met. Hard Mater. 23350

[5] Ivanov V V, Blokhina I A and Kirik S D 2014 Russ. J. Appl. Chem. 861650

[6] Kang S H and Kim D J 2007 J. Eur. Ceram. Soc. 27715
[7] Pierson H O and Mullendore A W 1982 Thin Solid Films 9599

[8] Bača L' and Stelzer N 2008 J. Eur. Ceram. Soc. 28907

[9] Gu Y, Qian Y, Chen L and Zhou F 2003 J. Alloys Compd. 352325

[10] Hwang Y and Lee J K 2002 Mater. Lett. 541

[11] Cheng Y, Shigeta M, Choi S and Watanabe T 2012 Chem. Eng. J. 183483

[12] Patil K C, Aruna S T and Mimani T 2002 Curr. Opin. Solid State Mater. Sci. 6507

[13] Varma A and Mukasyan A S 2004 Korean J. Chem. Eng. 21527

[14] Liu G, Li J and Chen K 2013 Int. J. Refract. Met. Hard Mater. 3990

[15] Sangshetti R M, Hiremath V A and Jali V M 2011 Bull. Mater. Sci. 341027

[16] Novikov N P, Borovinskaya I P and Merzhanov A G 1975 Combustion process in chemical technology metallurgy (ed) A G Merzhanov (Chernogolovka, Moscow) p 174

[17] Moore J J and Feng H J 1995 Prog. Mater. Sci. 39243

[18] Yeh C L and Li R F 2009 Chem. Eng. J. 147405

[19] Nozari A, Ataie A and Heshmati-Manesh S 2012 Mater. Charact. 7396

[20] Li J, Cai Z, Guo H, Xu B and Li L 2009 J. Alloys Compd. 479803

[21] Meyers M, Olevsky E, Ma J and Jamet M 2001 Mater. Sci. Eng. A 31183

[22] Mishra S K, Gokuul V and Paswan S 2014 Int. J. Refract. Met. Hard Mater. 4319

[23] Weimin W, Zhengyi F, Hao W and Runzhang Y 2002 J. Mater. Process. Technol. 128162

[24] Niyomwas S, Chaichana N, Memongkol N and Wannasin J 2008 Songklanakarin J. Sci. Technol. 30233

[25] Bilgi E, Çamurlu H E, Akgün B, Topkaya Y and Sevinç N 2008 Mater. Res. Bull. 43873

[26] Wang H Y, Jiang Q C, Zhao Y G and Zhao F 2004 J. Alloys Compd. 3794

[27] Khanra A K, Pathak L C, Mishra S K and Godkhindi M M 2004 Mater. Lett. 58733

[28] Derin B, Demircan U and Yücel O 2007 Metall. Mater. Eng. 447

[29] Demircan U, Derin B and Yücel O 2007 Mater. Res. Bull. 42312

[30] Aminikia B 2013 Chiang Mai J. Sci. 40274

[31] Sakaki M, Karimzadeh Behnami A and Bafghi M S 2014 Int. J. Refract. Met. Hard Mater. 44142

[32] Hoseinpur A, Bafghi M Sh, Vahdati Khaki J, Jalaly M and Sakaki M 2015 Int. J. Refract. Met. Hard Mater. 50191

[33] Ganesh I, Johnson R, Rao G V N, Mahajan Y R, Madavendra S S and Reddy B M 2005 Ceram. Int. 3167

[34] Mangalaraja R V, Ramam K V S, Ravi J and Camurri C P 2007 Mater. Sci. Pol. 251075

[35] Jones D A, Lelyveld T P, Mavrofidis S D, Kingman S W and Miles N J 2002 Resour. Conserv. Recycl. 3475

[36] Chandrasekaran S, Ramanathan S and Basak T 2012 AIChE J. 58330 
[37] Thostenson E T and Chou T-W 1999 Composites Part A: Appl. S. 301055

[38] Haque K E 1999 Int. J. Miner. Process. 571

[39] Agrawal D K 1998 Curr. Opin. Solid State Mater. Sci. 3480

[40] Farhadinia F and Sedghi A 2014 Metall. Mater. Trans. A 453125

[41] Mousavian R T, Sharafi S and Shariat M H 2011 Int. J. Refract. Met. Hard Mater. 29281
[42] Cullity B D and Stock S R 1978 Elements of X-ray diffraction (Massachusetts, USA: Addison-Wesley)

[43] http://www.crct.polymtl.ca/reacweb_plus.php

[44] Lee J H, Seo D H, Won C W, Borovinskaya I P and Vershinnikov V I 2001 J. Mater. Sci. 365311

[45] Aruna S T and Mukasyan A S 2008 Curr. Opin. Solid State Mater. Sci. 1244

[46] Borovinskaya I P, Ignat T I, Vershinnikov V I, Khurtina G G and Sachkova N V 2003 Inorg. Mater. 39588 